\title{
An Unusual Case of DMEK Graft Loss into the Vitreous and Its Successful Retrieval and Survival
}

\author{
Khaled Helaiwa $^{a} \quad$ Kai Januschowski ${ }^{a, b} \quad$ Karl T. Boden ${ }^{a}$ \\ Annekatrin Rickmann ${ }^{\mathrm{a}}$ \\ aKnappschaft Eye Clinic Sulzbach, Knappschaft Hospital Saar, Sulzbach/Saar, Germany; \\ ${ }^{b}$ Centre for Ophthalmology, Eberhard-Karls-University Tübingen, Tübingen, Germany
}

\section{Keywords}

Descemet membrane endothelial keratoplasty - Vitrectomy · Graft loss · Scleral-fixated intraocular lens

\begin{abstract}
Purpose: The aim of this article is to report an unusual case of postoperative graft loss into the vitreous cavity after Descemet membrane endothelial keratoplasty (DMEK) in a patient with an unstable iris-lens diaphragm (scleral-fixated intraocular lens [sf-IOL]) and its successful retrieval with a favourable outcome. Methods: This is a retrospective case report. Results: DMEK procedure was performed in a vitrectomized eye of an 80-year-old woman with pre-existing sf-IOL due to pseudophakic bullous keratopathy. In the setting of an inadvertently created oversized Ando iridectomy and unstable iris-lens diaphragm due to sf-IOL, repeated loss of an anterior chamber gas tamponade occurred. At the 3rd postoperative day, the patient noticed a change in visual perception, and we could detect a loss of the graft into the vitreous via Bscan ultrasound. A 23-G vitrectomy was performed promptly to recover the graft using a bimanual hand-over-hand technique. Six months after DMEK, the patient had a clear cornea without dehiscences with a central corneal thickness of $533 \mu \mathrm{m}$ and endothelial cell count of 1,219 cells $/ \mathrm{mm}^{2}$. Conclusions: This case demonstrates the possibility of graft recovery from the vitreous after DMEK and subsequent corneal clearing despite unstable iris-lens diaphragm and vitrectomized eye.

(C) 2018 The Author(s)

Published by S. Karger AG, Basel
\end{abstract}




\section{Introduction}

Descemet membrane endothelial keratoplasty (DMEK) is a surgical method to correct endothelial dysfunction by replacing selectively the damaged endothelium with Descemet's membrane [1]. Despite predictable clinical outcomes and good reproducibility, DMEK is still challenging due to certain morphological features of the eye. These include anatomy of the anterior chamber, condition of the iris-lens diaphragm and the status of the vitreous [2]. In general, a shallow or very deep anterior chamber can make the handling and unfolding of the graft difficult [2]. Furthermore, a stable iris-lens diaphragm is required for air injection into the anterior chamber to unfold and push the graft against the posterior surface of the corneal stroma [2]. Therefore, DMEK with a potentially unstable intraocular lens (IOL), like a scleralfixated IOL (sf-IOL), has an increased risk for complications [3].

We present, to our knowledge as a first description, a case of graft loss into the vitreous in an eye with sf-IOL with subsequent graft recovery and corneal clearance.

\section{Case Report}

In 2017, an 80-year-old woman was referred with a complaint of worsening blurry vision in the left eye due to corneal decompensation following a complicated history: a z-sutured sfIOL [4] was inserted 2 months earlier after IOL loss due to zonular insufficiency. Her best corrected visual acuity (decimal) was 0.8 at the right eye and 0.05 at the left eye. Slit-lamp examination was remarkable for epithelial and stromal oedema with a corneal thickness of $671 \mu \mathrm{m}$ (Pentacam, Oculus, Germany), but no discernible endothelial cells could be imaged in the left eye by non-contact specular microscopy. The patient had epiretinal gliosis and medically controlled primary open-angle glaucoma with a cup disc ratio of 0.7 . The intraocular pressure was $12 / 14 \mathrm{~mm} \mathrm{Hg}$ (Goldmann applanation tonometer), respectively. Her medical history was unremarkable except for systemic hypertension.

We performed DMEK surgery according to our standard procedure [5] (graft donor endothelial cell count 2,258 cells $/ \mathrm{mm}^{2}$ ) (Topcon, Tokyo, Japan) using 20\% sulphur hexafluoride (SF6) tamponade under parabulbar anaesthesia. Descemetorhexis and the graft were sized $8 \mathrm{~mm}$. Intraoperatively, the attempted iridectomy (IE) with De Wecker scissors was unsuccessful due to difficult iris grasping in the presence of a deep anterior chamber. Therefore, we had to perform the Ando IE with a vitreous cutter, resulting in an inadvertently huge size of IE. Regardless of the complicated intraoperative situation, the graft was placed correctly, and the anterior chamber was filled with $20 \%$ SF6 gas. Postoperatively, the patient had to stay in supine position.

At the first postoperative day, anterior chamber tamponade was missing, so that we performed rebubbling with $20 \%$ SF6. Nevertheless, there was again a lack of gas tamponade in the anterior chamber after repeated rebubbling, and a reliable statement on the position of the graft could not be made due to persistent corneal oedema in the further postoperative course (Fig. 1a). On the 3rd postoperative day, the patient reported a recent change in visual perception with a rolled-up shadow swimming like a floater. However, as the view was difficult due to the corneal oedema, we did ultrasonographic assessment of the eye, localising the dislocated graft in the vitreous (Fig. 2). On the same day, a 23-G pars plana vitrectomy with $20 \%$ SF6 tamponade was performed, achieving an uncomplicated transplant recovery.

Intraoperatively, the graft could be gripped with an Eckardt forceps (Bausch \& Lomb $\mathrm{GmbH}$, Germany) and relocated into the anterior chamber using inverse forceps in a hand- 
over-hand technique, transferring the transplant through the IE into the anterior chamber. The rolled-up graft was unfolded with a Göttinger spatula and irrigation cannula (Geuder, Heidelberg, Germany). The correct orientation of the graft could be determined by the curl tendency. All sclerotomies were sutured with 8.0 Vicryl sutures. To prevent any further re-dislocation, we repeated anterior chamber tamponade by rebubbling again on the 1st and 2nd postoperative day. The patient had to stay in strict supine position. On the tenth day after the initial DMEK, the graft remained well, despite a lack of anterior chamber tamponade (Fig. 1b). With continued postoperative treatment with Inflanefran eye drops (Prednisolone acetate, Allergan Pharmaceuticals, Ireland) 6 times a day, corneal clearing was noticed on follow-up at 2 weeks postoperatively with a best corrected visual acuity of 0.2 .

Further planned visits at 2, 3 and 6 months showed clear cornea without graft dehiscence (Fig. 1c, Fig. 3). At the final follow-up at 6 months, best corrected visual acuity was 0.4 (decimal), intraocular pressure $8 \mathrm{~mm} \mathrm{Hg}$ and the corneal thickness $533 \mu \mathrm{m}$. The donor endothelial cell density decreased from 2,258 cells $/ \mathrm{mm}^{2}$ preoperatively to 1,219 cells $/ \mathrm{mm}^{2} 6$ months after DMEK (Fig. 4). A limiting factor of visual acuity is a pre-existing glaucoma and epiretinal gliosis with metamorphopsia. Because of social issues, the patient did not want further surgical procedures.

\section{Discussion}

Even if complications remain low in DMEK compared to other keratoplasty techniques, certain anatomical features of the eye can cause complications and affect rebubbling rates. We were able to demonstrate in this case report that a graft loss can occur through the compromised iris-lens diaphragm in the presence of iris deficiency created by inadvertent large-sized IE. In such situations, the successful survival of the graft could be achieved without the need for externalization of the graft. To the best of our knowledge, this is the first reported case of DMEK graft loss into the vitreous with successful graft recovery.

Afshari et al. [6] reported a series of cases of Descemet stripping automated endothelial keratoplasty (DSAEK) with dislocated donor grafts into the posterior segment. This is a rare complication of DSAEK surgery which could lead to permanent vision loss. Graft dislocations occurred especially in eyes which had undergone previous vitrectomy and complicated intraocular lens placement or which were aphakic. In this particular case series, the final visual acuities after retrieval ranged from 20/30 to no light perception. Afshari et al. [6] concluded that better postoperative results seem to be associated with prompt removal of the posteriorly dislocated graft. Similarly, in our present case, a good postoperative outcome was achieved following the prompt intervention. However, the final visual outcome was limited by coexisting morbidities of glaucoma and epiretinal membrane.

An unstable iris-lens diaphragm increases the risk of dropping the graft into the vitreous during DSEAK [6]. As the DMEK graft is thinner than the DSEAK graft, the risk of dislocation in DMEK is higher [2]. In eyes with an unstable iris-lens diaphragm, the air bubble tends to move behind the iris and scleral-sutured IOL, making the attachment of the graft difficult [7]. To avoid complications of graft dislocation, Weller et al. [2] suggested a 2-step approach with initial stabilisation of the iris-lens diaphragm and secondary DMEK. Likewise, Röck et al. [3] showed that DMEK can be successfully performed in the presence of sf-IOL by simulated digital pressure in the equatorial region and tapping of the corneal surface. In our case, in the presence of sf-IOL in a vitrectomized eye, the instability was further worsened intraoperatively by the inadvertent creation of a large-sized IE. Perhaps, a preoperative laser iridotomy 
and pre-recognition of the presence of atrophic iris could have averted this. Wells at al. [8] reported a case of intraoperative graft dislocation and a novel hand-over-hand retrieval method from the retinal surface for intraoperatively dislocated DSEAK grafts. We employed this technique without any need for externalization in the re-surgery procedure performed 3 days later in the case of DMEK graft loss.

Another anatomical difficulty in DMEK are vitrectomized eyes [9]. Those eyes might be susceptible to recurrent globe collapse on intraoperative manipulation due to lack of posterior support [9]. Nevertheless, Yoeruek et al. [9] and Weller et al. [2] were able to show in retrospective evaluations that DMEK is possible and successful despite complex preoperative situations, such as already vitrectomized eyes. Likewise, in our case, we were able to attach the donor graft successfully despite vitrectomy and unstable iris-lens diaphragm.

The repeated interventions and increased manipulation of the donor graft could affect the graft's endothelial cell viability [9]. The difficulties during the unfolding and manipulation of the donor graft contribute to graft failure [10]. The importance of avoiding a possible contact with endothelium has been well demonstrated by Parekh et al. [11], showing more than $90 \%$ endothelial cell loss in uncovered areas. In this case, endothelial cell density decreased by $46 \%$ after 6 months of DMEK. Due to manipulation and possible direct contact, this endothelial cell loss is higher than in other research groups, reporting an average endothelial cell loss of $30 \%$ within the first 6 months [12-14]. This increased cell loss could lead to a graft failure as a result. Although it has been shown in some reports that a conscious or accidental central Descemetorhexis without keratoplasty can lead to a recovery of the stromal oedema $[15,16]$, and even very large central corneal endothelial defects could become repopulated with endothelial cells in patients with Fuchs endothelial dystrophy [17], Lee and Munir [18] could show that the potential for endothelial cell regeneration might be limited and could result in a renewed corneal decompensation in the clinical long-term course of 2.5 years. Therefore, continuous observation of the patient is necessary to timely detect renewed indication for keratoplasty [18].

This case demonstrates the possibility of graft recovery from the vitreous after DMEK, despite unstable iris-lens diaphragm and vitrectomized eye, by hand-over-hand technique without externalization of the graft and subsequent corneal clearing. Long-term observation of the patient is desirable because of possible further endothelial cell loss and subsequent corneal decompensation.

\section{Statement of Ethics}

Compliance with ethical standards. The patient signed an informed consent form.

\section{Disclosure Statement}

All authors certify that they have no affiliations with or involvement in any organization or entity with any financial interest (such as honoraria; educational grants; participation in speakers' bureaus; membership, employment, consultancies, stock ownership, or other equity interest; and expert testimony or patent-licensing arrangements), or non-financial interest (such as personal or professional relationships, affiliations, knowledge or beliefs) in the subject matter or materials discussed in this article. 


\section{Case Reports in Ophthalmology}

\section{References}

1 Ham L, Balachandran C, Verschoor CA, van der Wees J, Melles GR. Visual rehabilitation rate after isolated descemet membrane transplantation: descemet membrane endothelial keratoplasty. Arch Ophthalmol. 2009 Mar;127(3):252-5.

2 Weller JM, Tourtas T, Kruse FE. Feasibility and Outcome of Descemet Membrane Endothelial Keratoplasty in Complex Anterior Segment and Vitreous Disease. Cornea. 2015 Nov;34(11):1351-7.

3 Röck D, Röck T, Bartz-Schmidt KU, Yoeruek E. Descemet membrane endothelial keratoplasty in cases with existing scleral-sutured and iris-sutured intraocular lenses. BMC Ophthalmol. 2014 Jan;14(1):6.

4 Szurman P, Petermeier K, Aisenbrey S, Spitzer MS, Jaissle GB. Z-suture: a new knotless technique for transscleral suture fixation of intraocular implants. Br J Ophthalmol. 2010 Feb;94(2):167-9.

5 Szurman P, Januschowski K, Rickmann A, Damm LJ, Boden KT, Opitz N. Novel liquid bubble dissection technique for DMEK lenticule preparation. Graefes Arch Clin Exp Ophthalmol. 2016 Sep;254(9):1819-23.

6 Afshari NA, Gorovoy MS, Yoo SH, Kim T, Carlson AN, Rosenwasser GO, Griffin NB, McCuen BW 2nd, Toth CA, Price FW Jr, Price M, Fernandez MM. Dislocation of the donor graft to the posterior segment in descemet stripping automated endothelial keratoplasty. Am J Ophthalmol. 2012 Apr;153(4):638-42, 642.e1-2.

7 Jastaneiah SS. Descemet's Stripping-Automated Endothelial Keratoplasty for Traumatic Aniridia and Aphakia. Case Rep Ophthalmol Med. 2012;2012:982657.

8 Wells JA 4th, Aldave AJ, Tsui I. Surgical technique: hand-over-hand retrieval of a posteriorly dislocated DSAEK graft in an eye with an iris reconstruction lens. Ophthalmic Surg Lasers Imaging Retina. 2013 Nov;44(6):569-71.

9 Yoeruek E, Rubino G, Bayyoud T, Bartz-Schmidt KU. Descemet membrane endothelial keratoplasty in vitrectomized eyes: clinical results. Cornea. 2015 Jan;34(1):1-5.

10 Droutsas K, Giallouros E, Melles GR, Chatzistefanou K, Sekundo W. Descemet membrane endothelial keratoplasty: learning curve of a single surgeon. Cornea. 2013 Aug;32(8):1075-9.

11 Parekh M, Ruzza A, Salvalaio G, Ferrari S, Camposampiero D, Busin M et al. Descemet membrane endothelial keratoplasty tissue preparation from donor corneas using a standardized submerged hydro-separation method. Am J Ophthalmol. 2014 Aug;158(2):277-285.e1.

12 Parker J, Dirisamer M, Naveiras M, Ham L, van der Wees J, Melles GR. Endothelial cell density after Descemet membrane endothelial keratoplasty: 1- to 4-year follow-up. Am J Ophthalmol. 2011 Jun;151(6):11071107.e2.

13 Price MO, Giebel AW, Fairchild KM, Price FW Jr. Descemet's membrane endothelial keratoplasty: prospective multicenter study of visual and refractive outcomes and endothelial survival. Ophthalmology. 2009 Dec;116(12):2361-8.

14 Rickmann A, Opitz N, Szurman P, Boden KT, Jung S, Wahl S, Haus A, Damm LJ, Januschowski K. Clinical Comparison of Two Methods of Graft Preparation in Descemet Membrane Endothelial Keratoplasty. Curr Eye Res. 2018 Jan;43(1):12-17.

15 Borkar DS, Veldman P, Colby KA. Treatment of Fuchs Endothelial Dystrophy by Descemet Stripping Without Endothelial Keratoplasty. Cornea. 2016 Oct;35(10):1267-73.

16 Shah RD, Randleman JB, Grossniklaus HE. Spontaneous corneal clearing after Descemet's stripping without endothelial replacement. Ophthalmology. 2012 Feb;119(2):256-60.

17 Dirisamer M, Ham L, Dapena I, van Dijk K, Melles GR. Descemet membrane endothelial transfer: "freefloating" donor Descemet implantation as a potential alternative to "keratoplasty". Cornea. 2012 Feb;31(2):194-7.

18 Lee HJ, Munir WM. Eventual Endothelial Failure After Initial Corneal Clearing After a Detached Endothelial Graft in Fuchs Dystrophy. Cornea. 2017 Feb;36(2):241-243. 


\section{Case Reports in Ophthalmology}

\begin{tabular}{l|l}
\hline Case Rep Ophthalmol 2018;9:381-387 \\
\hline DOI: 10.1159/000492173 & $\begin{array}{l}\text { @ 2018 The Author(s). Published by S. Karger AG, Basel } \\
\text { www.karger.com/cop }\end{array}$ \\
\hline
\end{tabular}

Helaiwa et al.: An Unusual Case of DMEK Graft Loss into the Vitreous and Its Successful Retrieval and Survival
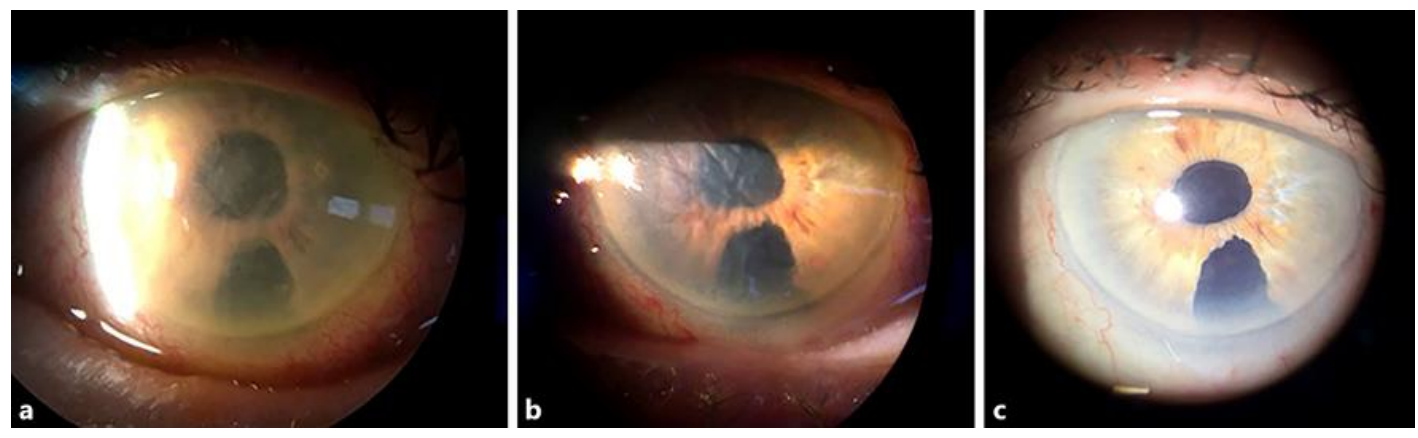

Fig. 1. Slit-lamp photo of the left eye of the patient. On the 3rd postoperative day, there is a stromal and epithelial oedema with Descemet folds with resulting uncertainty of the location of the graft (a). Six days after vitrectomy, beginning of corneal clearing was seen (b). Three months after Descemet membrane endothelial keratoplasty, a clear cornea with an adjacent graft was achieved (c).
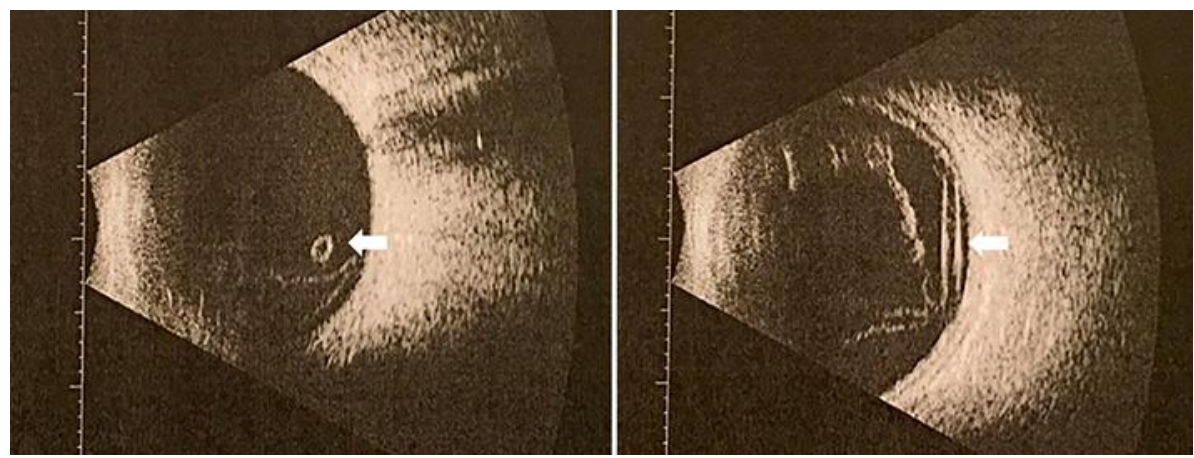

Fig. 2. B-scan of the left eye with a scrolled graft in the vitreous (arrow) 3 days after Descemet membrane endothelial keratoplasty.

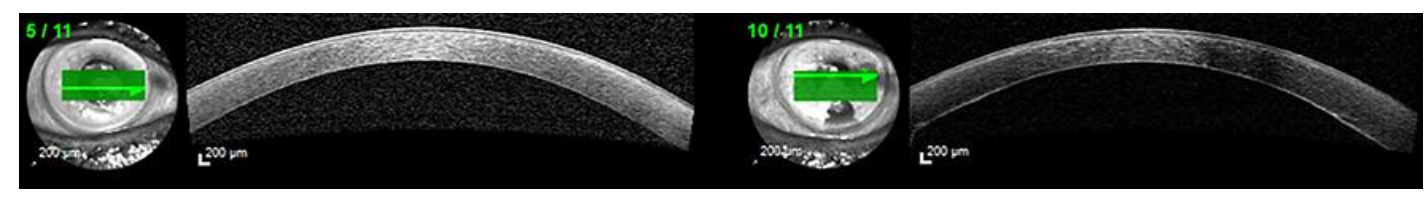

Fig. 3. Anterior-segment optical coherence tomography of the right and left eye 6 months after Descemet membrane endothelial keratoplasty. The left eye shows an attached graft with no dehiscences. 
Case Reports in
Ophthalmology
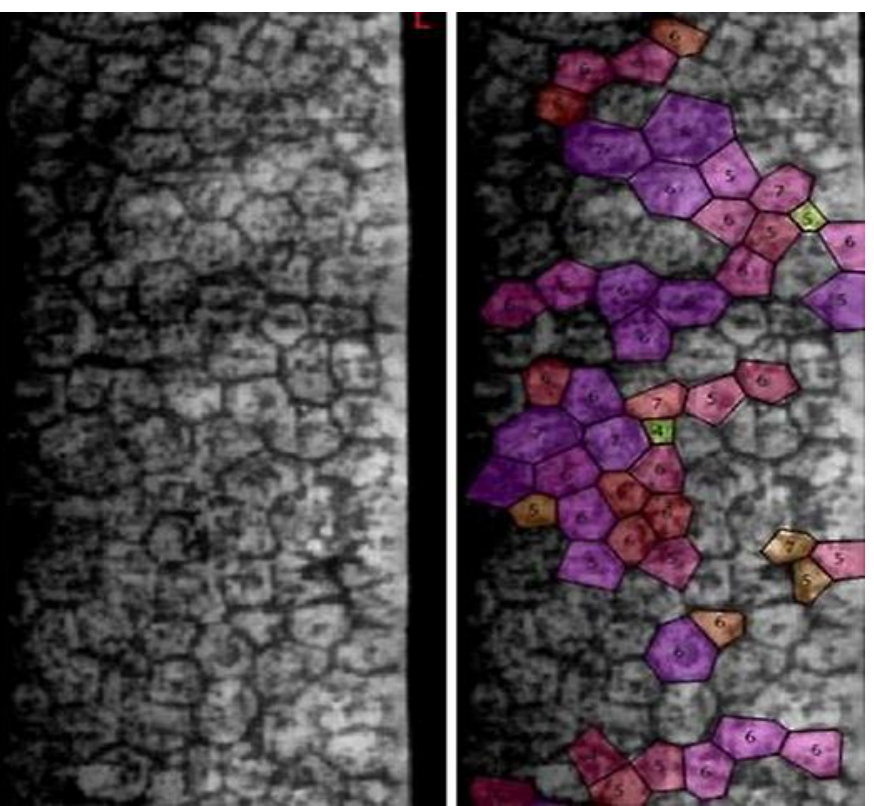

Fig. 4. Endothelial cell count 6 months after Descemet membrane endothelial keratoplasty, showing polymorphism and 1,219 cells $/ \mathrm{mm}^{2}$.

Helaiwa et al.: An Unusual Case of DMEK Graft Loss into the Vitreous and Its Successful Retrieval and Survival www.karger.com/cop 